\title{
LETTER
}

\section{Calculation of mechanical power for pressure-controlled ventilation}

\author{
Tobias Becher $^{1^{*}}$ (D, M. van der Staay ${ }^{2}$, D. Schädler ${ }^{1}$, I. Frerichs ${ }^{1}$ and N. Weiler ${ }^{1}$
}

(0) 2019 Springer-Verlag GmbH Germany, part of Springer Nature

\section{Dear Editor,}

The mechanical power (MP) is a single variable encompassing important ventilator-related causes of lung injury that can be calculated using a set of parameters routinely measured during volume-controlled ventilation (VCV) [1]. A recent analysis of two large databases revealed that high MP is independently associated with mortality in critically ill patients on mechanical ventilation [2]. As the equation for calculation of MP used for these analyses is based on the assumption of VCV with a linear rise of airway pressure $\left(P_{\text {aw }}\right)$ during inspiration, it is not suitable for calculating MP during pressure-controlled ventilation (PCV) [3]. Here, we describe two equations for estimating MP during PCV and assess their validity in patients ventilated with this mode.

We retrospectively analyzed PCV data of patients enrolled in two previously published studies $[4,5]$. We excluded datasets obtained during assisted spontaneous breathing and during VCV.

Under the assumption of an ideal "square wave" $P_{\mathrm{aw}}$ during inspiration, MP during PCV was calculated according to the simplified equation

$$
\mathrm{MP}_{\mathrm{PCV}}=0.098 \cdot \mathrm{RR} \cdot V_{\mathrm{T}} \cdot\left(\Delta P_{\text {insp }}+\mathrm{PEEP}\right),
$$

where $\Delta P_{\text {insp }}$ is the change in $P_{\text {aw }}$ during inspiration, PEEP is the positive end-expiratory pressure (both $\mathrm{cmH}_{2} \mathrm{O}$ ), $V_{\mathrm{T}}$ is the tidal volume (l) and $\mathrm{RR}$ is the respiratory rate $(1 / \mathrm{min})$, with 0.098 as a correction factor to obtain the result in $\mathrm{J} / \mathrm{min}$.

\footnotetext{
*Correspondence: tobias.becher@uksh.de

${ }^{1}$ Department of Anesthesiology and Intensive Care Medicine, University Medical Centre Schleswig-Holstein, Campus Kiel, Arnold-Heller-Str. 3, Haus 12, 24105 Kiel, Germany

Full author information is available at the end of the article
}

Taking into account inspiratory pressure rise time ( $\left.T_{\text {slope }}\right)$, MP was additionally calculated according to the comprehensive equation

$$
\begin{aligned}
M P_{\mathrm{PCV}(\text { slope })} & =0.098 \cdot \mathrm{RR} \cdot\left[\left(\Delta P_{\text {insp }}+\mathrm{PEEP}\right) \cdot V_{\mathrm{T}}-\Delta P_{\text {insp }}^{2} \cdot C .\right. \\
& \left.\left(0.5-\frac{R \cdot C}{T_{\text {slope }}}+\left(\frac{R \cdot C}{T_{\text {slope }}}\right)^{2} \cdot\left(1-\mathrm{e}^{\frac{-T_{\text {slope }}}{R \cdot C}}\right)\right)\right]
\end{aligned}
$$

where $C$ is the compliance $\left(\mathrm{l} / \mathrm{cmH}_{2} \mathrm{O}\right)$ and $R$ is the resistance $\left(\mathrm{cmH}_{2} \mathrm{O} / \mathrm{l} / \mathrm{s}\right)$. The derivation of both equations and the determination of respiratory mechanics during $\mathrm{PCV}$ are outlined in the ESM.

To obtain reference values $\left(\mathrm{MP}_{\text {ref }}\right)$, data of $P_{\text {aw }}$ and flow recorded by the ventilator (Evita XL; Dräger, Lübeck, Germany) at a sampling rate of $100 \mathrm{~Hz}$ were integrated to calculate the area of the pressure-volume loop and subsequently multiplied by $0.098 \cdot \mathrm{RR}$ to obtain the result in $\mathrm{J} /$ min. For each patient, one average value of $\mathrm{MP}_{\text {ref }}, \mathrm{MP}_{\mathrm{PCV}}$ and $\mathrm{MP}_{\mathrm{PCV} \text { (slope) }}$ was calculated from all breaths recorded during a period of PCV with unchanged ventilator settings. Intra-individual variability was assessed by calculating the coefficient of variation between all breaths analyzed during this period.

$\mathrm{MP}_{\mathrm{PCV}}$ and $\mathrm{MP}_{\mathrm{PCV}(\text { slope })}$ were compared to $\mathrm{MP}_{\text {ref }}$ by linear regression and the Bland-Altman method comparison. Numerical results are expressed as mean \pm standard deviation.

We analyzed PCV datasets obtained from 42 patients (age $55 \pm 18$ years; 29 male; height $174 \pm 9 \mathrm{~cm} ; \mathrm{PaO}_{2} / \mathrm{FiO}_{2}$ $195 \pm 78 \mathrm{mmHg} ; 29$ patients with ARDS) ventilated with external PEEP of $8 \pm 5 \mathrm{cmH}_{2} \mathrm{O}, \mathrm{RR} 14 \pm 4 / \mathrm{min}, \Delta P_{\text {insp }}$ $14 \pm 4 \mathrm{cmH}_{2} \mathrm{O}, \mathrm{V}_{\mathrm{T}} 545 \pm 161 \mathrm{ml}$ and $\mathrm{T}_{\text {slope }} 0.2 \pm 0.03 \mathrm{~s}$. Calculated auto-PEEP was $0.81 \pm 0.77 \mathrm{cmH}_{2} \mathrm{O}$.

On average, $\mathrm{MP}_{\text {ref }}$ was $15.6 \pm 6.9 \mathrm{~J} / \mathrm{min}$. With the simplified equation, we calculated values for $\mathrm{MP}_{\mathrm{PCV}}$ of $16.3 \pm 7.1 \mathrm{~J} / \mathrm{min}$, which were highly correlated to

\section{6 Springer}


$\mathrm{MP}_{\text {ref }}\left(r^{2}=0.981\right.$; bias $+0.73 \mathrm{~J} / \mathrm{min} ; 95 \%$ limits of agreement (LoA) -1.48 to $+2.93 \mathrm{~J} / \mathrm{min}$; Fig. 1a, b). With the comprehensive equation, the determined values of $\mathrm{MP}_{\mathrm{PCV}(\text { slope) }}$ averaged $15.6 \pm 6.9 \mathrm{~J} / \mathrm{min}$, almost identical to $\mathrm{MP}_{\text {ref }}\left(r^{2}=0.985\right.$; bias $+0.03 \mathrm{~J} / \mathrm{min}$; $95 \%$ LoA -1.91 to $+1.98 \mathrm{~J} / \mathrm{min}$; Fig. $1 \mathrm{c}, \mathrm{d})$. The between-breath coefficients of variation for $\mathrm{MP}_{\text {ref }}, \mathrm{MP}_{\mathrm{PCV}}$ and $\mathrm{MP}_{\mathrm{PCV} \text { (slope) }}$ were $0.02 \pm 0.02,0.04 \pm 0.05$ and $0.03 \pm 0.03$, respectively.
The simplified equation allows estimation of MP for PCV with a small bias caused by disregarding $T_{\text {slope }}$. The comprehensive equation corrects this bias but requires knowledge of $T_{\text {slope }}, R$ and $C$. If only $V_{\mathrm{T}}, \mathrm{RR}, \mathrm{PEEP}$ and $\Delta P_{\text {insp }}$ are known, the simplified equation may still yield acceptable results for most clinical situations.

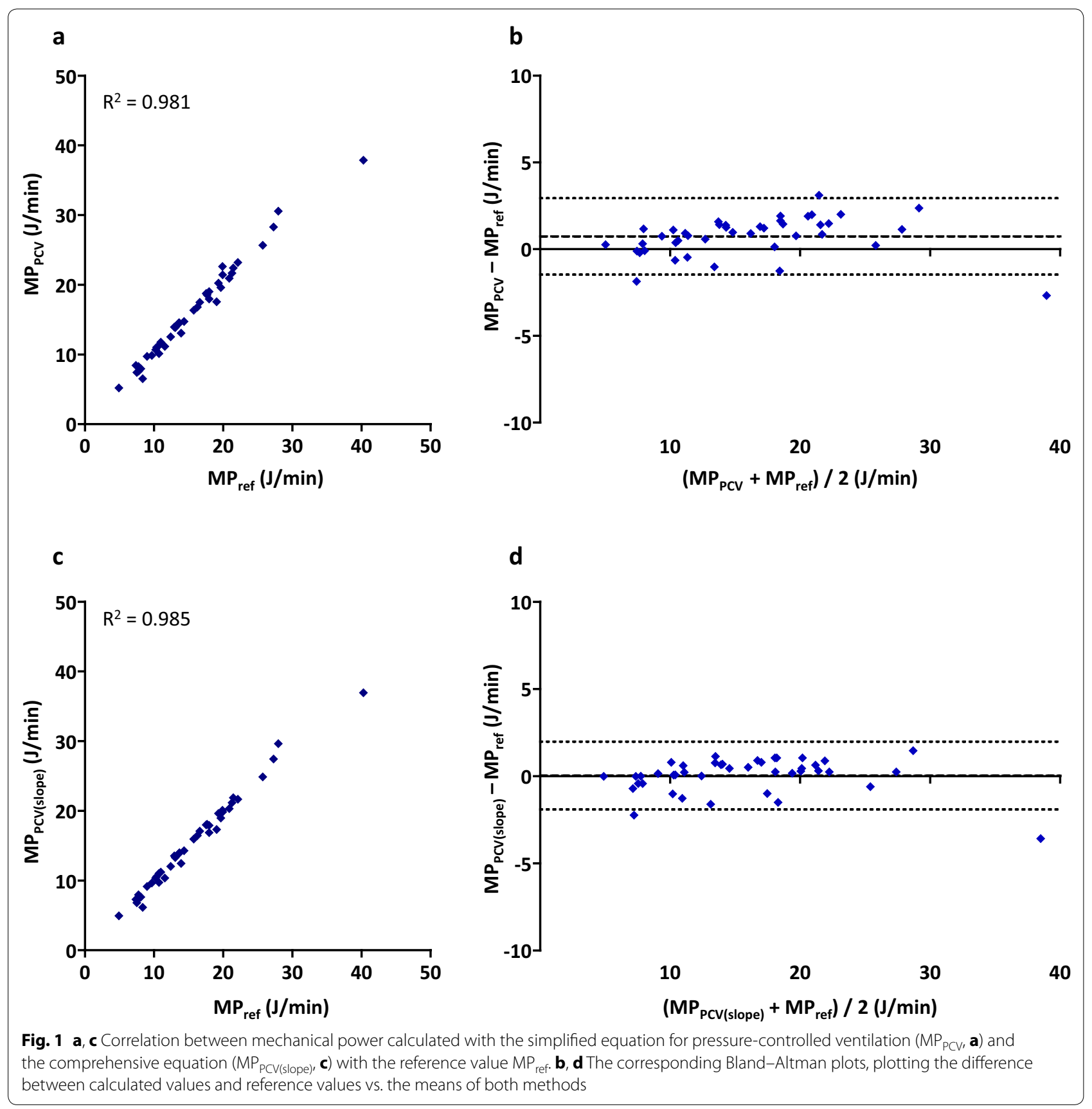




\section{Electronic supplementary materia}

The online version of this article (https://doi.org/10.1007/s00134-019-05636-8)

contains supplementary material, which is available to authorized users.

\section{Author details}

${ }^{1}$ Department of Anesthesiology and Intensive Care Medicine, University Medical Centre Schleswig-Holstein, Campus Kiel, Arnold-Heller-Str. 3, Haus 12, 24105 Kiel, Germany. ${ }^{2}$ IMT AG, Gewerbestrasse 8, 9470 Buchs, Switzerland.

\section{Compliance with ethical standards}

\section{Conflicts of interest}

Tobias Becher and Dirk Schädler received lecture fees from Drägerwerk AG \& Co. KGaA (Lübeck, Germany). Matthias van der Staay is an employee of imt and works for imtmedical, Buchs, Switzerland. The other authors report no conflicts of interest.

\section{Publisher's Note}

Springer Nature remains neutral with regard to jurisdictional claims in published maps and institutional affiliations.

Accepted: 2 May 2019

Published online: 17 May 2019

\section{References}

1. Gattinoni L, Tonetti T, Cressoni M et al (2016) Ventilator-related causes of lung injury: the mechanical power. Intensive Care Med 42:1567-1575

2. Neto AS, Deliberato RO, Johnson AW et al (2018) Mechanical power of ventilation is associated with mortality in critically ill patients: an analysis of patients in two observational cohorts. Intensive Care Med 44:1914-1922

3. Zhao Z, Frerichs I, He H et al (2019) The calculation of mechanical power is not suitable for intra-patient monitoring under pressure-controlled ventilation. Intensive Care Med. https://doi.org/10.1007/s00134-01905536-x

4. Pulletz S, Adler A, Kott M et al (2012) Regional lung opening and closing pressures in patients with acute lung injury. J Crit Care 27(27):323. e11-323.e18

5. Becher T, Bui S, Zick G et al (2014) Assessment of respiratory system compliance with electrical impedance tomography using a positive endexpiratory pressure wave maneuver during pressure support ventilation: a pilot clinical study. Crit Care 18:679 